CLINICAL STUDY

\title{
Benign fine-needle aspiration cytology of thyroid nodule: to repeat or not to repeat?
}

\author{
Filip Gabalec ${ }^{1}$, Jan Čáp ${ }^{1}$, Aleš Ryška ${ }^{2}$, Tomáš Vašátko ${ }^{1}$ and Věra Ceeová ${ }^{1}$ \\ ${ }^{1}$ Second Department of Internal Medicine and ${ }^{2}$ The Fingerland's Department of Pathology, Charles University Faculty of Medicine and Teaching Hospital in \\ Hradec Králové, Sokolská 581, 500-05 Hradec Králové, Czech Republic
}

(Correspondence should be addressed to F Gabalec; Email: gabalec@fnhk.cz)

\begin{abstract}
Context: Fine-needle aspiration cytology (FNAC) is the gold standard for evaluating thyroid nodules. It has a sensitivity rate of about $95 \%$, i.e. false negative results represent up to $5 \%$ of cases. The value of repeated FNAC during follow-up is still controversial.

Objective: To evaluate the usefulness of repeating the FNAC for initially benign nodules.

Design and methods: All 5017 patients who underwent FNAC of the thyroid nodule in years 1991-2008 were retrospectively evaluated.

Results: Repeated FNAC was performed in 574 nodules with initially benign results. The number of repetitions varied from one to six. Repeatedly benign results were found in 498 cases, and malignant/ suspicious results with initially benign cytology were found in 76 nodules (13.2\%). Carcinoma was present in 13 out of the 58 surgically treated malignant/suspicious results of initially benign cytology. Conclusions: A change from a benign FNAC result to a malignant/suspicious one was present in more than $13 \%$ of the patients with initially benign cytology; malignancy has been recognised on the basis of repeated FNAC in $2.3 \%$ patients. In the majority of cases, the repetition corrected wrong cytological interpretation of results other than colloidal goitre, especially Hashimoto's thyroiditis and regressive changes. We believe that repeating FNAC in patients with benign cytology in about a 1-year horizon can reduce the rate of undiagnosed tumours.
\end{abstract}

European Journal of Endocrinology $161933-937$

\section{Introduction}

Thyroid nodules represent a common problem in endocrinology, with an estimated prevalence of $4-7 \%$ in the adult population for palpable nodules. The prevalence is higher in women $(5 \%)$ than in men $(1 \%)$ (1). The prevalence of nodules found during autopsies, operations or ultrasound examinations is considerably higher and increases with age (2-4). The majority of nodules are benign. Cancer can be present in $3-10 \%$ of nodules, depending on age, gender, radiation exposure history, family history, and other factors (5). Over the last few years, many advances have been achieved in diagnosing thyroid nodules. In addition, various clinical and radiological features have been studied to increase detection rate of differentiated thyroid carcinoma. Unfortunately, these features lack specificity and sensitivity (6-9), and none have been so far recommended for a routine use (10). Fine-needle aspiration cytology (FNAC) is a well-established method for evaluating thyroid nodules. The indications for FNAC are well established and described in several different guidelines (11-13). Patients with benign results of FNAC should be followed up due to the known 5\% false negative rate of thyroid FNAC (14). Some discrepancies can be found in the current guidelines of three different endocrine societies (The American Association of Clinical Endocrinologists (AACE), The American Thyroid Association (ATA) and The European Thyroid Association) as well as among clinicians. One area where there is no consensus among authors is the need to repeat aspiration cytology in a patient with benign FNAC result. The aim of this study was to determine the usefulness of repeated FNAC in a large series of patients followed up for more than 10 years.

\section{Patients and methods}

Results of FNAC of thyroid nodules performed in 5017 patients during a period from 1991 to 2008 at the Charles University, Faculty of Medicine and Teaching Hospital in Hradec Králové, were retrospectively analysed. The Ethic Committee of the Charles University, Faculty of Medicine and Teaching Hospital in Hradec Králové, has approved the study. A total of 6009 cytological diagnoses were reviewed. All FNACs 


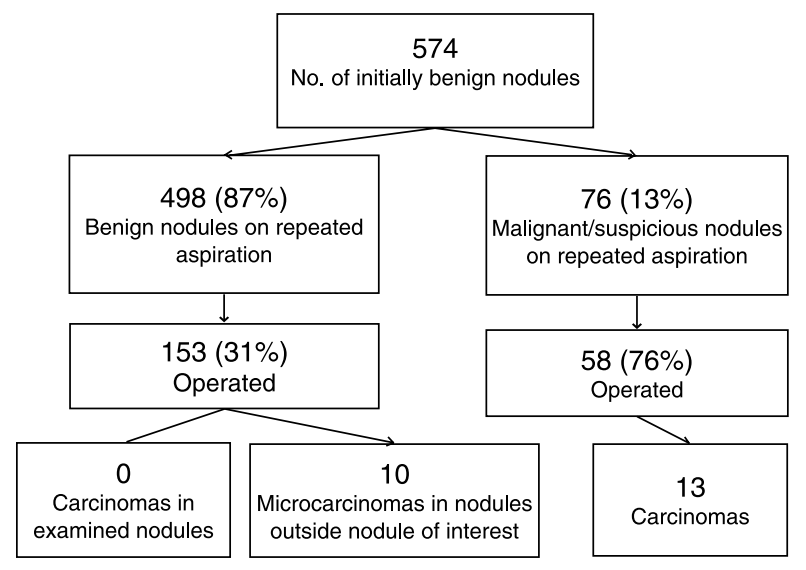

Figure 1 Results of 574 initially benign nodules after repeated FNAC are shown.

were performed under US guidance. Results of the FNAC were classified as unsatisfactory (non-diagnostic), benign and malignant/suspicious from malignancy (indeterminate). Unsatisfactory aspirates were excluded from further analysis. The results were evaluated as unsatisfactory if there were less than ten groups of cell, each containing at least ten elements. Benign aspirates included nodular goitres with or without regressive changes, and/or focal lymphocytic thyroiditis as well as Hashimoto's and de Quervain's subacute thyroiditis. The 'malignant/suspicious' category included follicular neoplasm, papillary carcinoma, anaplastic carcinoma, medullar carcinoma, lymphoma and metastatic carcinoma. These were diagnosed either as unequivocally malignant or with varying degrees of probability, and included uncertain findings that could not rule out malignancy. The pathological examination was performed after surgery (hemithyroidectomy or total thyroidectomy). The results were classified as benign (colloid nodular goitre, follicular adenoma, Hashimoto's thyroiditis) or malignant (follicular carcinoma, papillary carcinoma, anaplastic carcinoma, medullar carcinoma, lymphoma or metastatic carcinoma; 15, 16).

\section{Results}

Altogether 574 initially benign nodules were followed by repeated FNAC two or more times in $55(9.6 \%)$ men and $519(90.4 \%)$ women, aged from 15 to 92 years (mean 50.2, median 50). The clinical diagnosis of the subjects with initially benign FNAC result was euthyroid nodular goitre in 418 patients $(72.8 \%), 84$ (14.6\%) patients with nodules in Hashimoto's thyroiditis, 42 (7.3\%) with toxic nodular goitre, $27(4.7 \%)$ with cysts and three patients with subacute thyroiditis and nodules. Clinically, there were 501 euthyroid patients (87.3\%), $31(5.4 \%)$ with hypofunction and $42(7.3 \%)$ with hyperfunction. The indication was single nodule in 176 cases and dominant nodule in multinodular goitre in 398 patients. In cases with toxic multinodular goitre, the FNAC was repeated only if the nodule proved to be cold on scintigraphy. FNAC was repeated once in 400 cases, twice in 107, thrice in 49 , four times in 10 , five times in seven patients and six times in one patient. The aspiration was repeated in the patients with benign first FNAC followed up at our department, provided the patient agreed. However, the indication was by the investigating physician so selection bias is probable (cases with suspicious US characteristics, uncertain FNAC result and growing nodules were aspirated more frequently). Thyroxine suppression therapy of euthyroid nodules is not routinely used at our institution.

There were 574 initially benign nodules sized from 8 to $90 \mathrm{~mm}$ (median $14 \mathrm{~mm}$ ). Altogether 498 nodules had repeatedly benign cytological results. The histology was available in 153 of them $(30 \%)$ and all nodules proved to be benign. Microcarcinoma located distant from the aspirated lesion was found in ten patients.

The cytological result changed to 'malignant/ suspicious' in 76 nodules with initially benign cytology during the follow-up period. Fifty-eight $(76 \%)$ of these patients underwent surgery; malignancy was confirmed in 13 cases - four papillary carcinomas, three follicular variants of papillary carcinoma, four follicular carcinomas, one medullar carcinoma and one poorly differentiated carcinoma (Fig. 1).

The mean follow-up period was 7 years, with detailed data shown in Table 1.

\section{Discussion}

Many authors use four categories of cytological results (benign, indeterminate, malignant and unsatisfactory). We used only three categories, as mentioned above: i) unsatisfactory; ii) benign; and iii) malignant/suspicious from malignancy. This is due to the fact that both 'malignant' as well as 'suspicious/indeterminate' results have the same clinical impact - thyroid surgery is

Table 1 Mean time of follow-up in repeated fine-needle aspiration cytology (FNAC) and number of positive changes.

\begin{tabular}{|c|c|c|c|c|c|c|c|}
\hline No. of performed FNAC & 2 & 3 & 4 & 5 & 6 & 7 & Total \\
\hline No. of nodules & 400 & 107 & 49 & 10 & 7 & 1 & 574 \\
\hline Percentage of all 5017 FNAC & $7.97 \%$ & $2.13 \%$ & $0.98 \%$ & $0.20 \%$ & $0.14 \%$ & $0.02 \%$ & $11 \%$ \\
\hline $\begin{array}{l}\text { No. of results changed from } \\
\text { benign to suspicious }\end{array}$ & 48 & 17 & 8 & 3 & 3 & 0 & 79 \\
\hline Mean time from first FNAC (years) & 3.0 & 5.3 & 6.4 & 7.4 & 8.8 & 11.2 & 7.02 \\
\hline
\end{tabular}


Table 2 Summary of studies of changes in initially benign cytology.

\begin{tabular}{|c|c|c|c|c|c|c|}
\hline & $\begin{array}{l}\text { No. of initially } \\
\text { benign }\end{array}$ & $\begin{array}{l}\text { No. of results } \\
\text { changed to } \\
\text { suspicious }\end{array}$ & $\begin{array}{c}\text { Percentage } \\
(\%)\end{array}$ & Operated & Malignancy & $\begin{array}{c}\text { Percentage } \\
\text { (\%) }\end{array}$ \\
\hline Aguilar et al. (1998) (24) & 184 & 1 & 0.5 & 90 & 3 & 1.6 \\
\hline Cáp et al. (2000) (29) & 253 & 27 & 10.7 & 22 & 7 & 2.8 \\
\hline Dwarkanathan et al. (1993) (30) & 196 & 13 & 6.6 & 10 & 4 & 2.0 \\
\hline Erdogan et al. (1998) (25) & 216 & 3 & 1.4 & 3 & 3 & 1.4 \\
\hline Flanagan et al. (2006) (23) ${ }^{\mathrm{a}}$ & 57 & 23 & 40.4 & 23 & 9 & 15.8 \\
\hline Hamburger (1987) $(31)^{\mathrm{b}}$ & 205 & 18 & 8.8 & 10 & 6 & 2.9 \\
\hline Chehade et al. (2001) (21) & 235 & 12 & 5.1 & 9 & 2 & 0.9 \\
\hline Illouz et al. (2007) (22) & 282 & 35 & 12.4 & 31 & 7 & 2.5 \\
\hline Lucas et al. (1995) (24) & 135 & 0 & 0.0 & & 0 & 0.0 \\
\hline Menéndez Torre et al. (2007) (28) & 358 & 18 & 5.0 & 12 & 7 & 2.0 \\
\hline Merchant et al. (2000) (36) & 45 & 0 & 0.0 & 0 & 0 & 0.0 \\
\hline Mittendorf \& McHenry (1999) (32) & 45 & 4 & 8.9 & & 1 & 2.2 \\
\hline Morosini et al. (1996) (37) & 471 & 8 & 1.7 & 14 & 0 & 0.0 \\
\hline Orlandi et al. (2005) (27) & 306 & 7 & 2.3 & & & \\
\hline Shin et al. (2006) (26) & 187 & 44 & 23.5 & & 6 & 3.2 \\
\hline Gabalec present results (2009) & 574 & 76 & 13.2 & 58 & 13 & 2.3 \\
\hline Total & 3749 & 289 & 7.7 & & 68 & 1.8 \\
\hline
\end{tabular}

\section{${ }^{\mathrm{a} O n l y}$ operated.}

${ }^{\mathrm{b}}$ Adapted data.

indicated in both cases $(3,11,17)$. The main goal of thyroid FNAC is the early differentiation between nonmalignant and malignant nodules (18). FNAC is a well-established method and its reliability depends on several factors, such as the skill of the physician or the experience of the cytopathologist. Use of ultrasonography in FNAC increases significantly the sensitivity, specificity and accuracy compared with conventional palpation-guided FNAC (9). Thyroid FNAC sensitivity, specificity, false positive and false negative rates differ significantly among various authors. Sensitivity varies between 56 and $100 \%$, and specificity between 52 and $100 \%$. A positive predictive value is estimated to be $34-100 \%$, whereas a negative predictive value is $83-100 \%(9,15)$. Suspicious or clearly malignant results are an indication for surgery and histopathological evaluation of the lesion, while inadequate results should be followed by repeated aspiration. In terms of the follow-up of benign cytological results, no consensus has been reached so far. These different opinions are reflected in different recommendations in the guidelines of three important societies of endocrinology. The AACEs and Associatione Medici Endocrinologi guidelines suggest simple follow-up of cytologically benign thyroid nodules. Repeated ultrasonography is not recommended. Repeating FNAC should be performed only for enlarging nodules, recurrent cysts or for nodules not shrinking after thyroxine therapy. The ATA guidelines suggest clinical follow-up for 6-18 months, without US guidance for easily palpable benign nodules. FNAC repetition or surgery is reserved for enlarging nodules only. These and other differences among guidelines are well reviewed by Gharib (19). Some authors recommend repeating FNAC always when the nodule is enlarging, has more than $4 \mathrm{~cm}$ in diameter, shows no shrinkage of the nodule occurs after levothyroxine therapy and in cases of recurrent cysts.

Wiersinga has recommended repeating palpation and FNAC, 1 year after a benign FNAC result (20). During the last decade, several studies evaluated the risk of carcinoma in subsequent FNAC after initially benign cytology. The false negative rate can be reduced by repeating FNAC by $4.5-5.9 \%(21-23)$, from the initial $5.2-6.7$ to $0.8-1.3(21,22)$. Subsequent results have cumulatively changed in about $7 \%$ of the cases, and carcinoma was found in about $2 \%$. This relevant number of carcinomas can be detected by repeated FNAC according to many authors (21-32). Some authors tried to find out how many times FNAC should be repeated. Illouz (22) proposes a minimum of three adequate benign results as appropriate. However, some authors have reported low false negativity $(33,34)$, and declare no or only limited benefit from repeated FNAC (34-37). Data are summarised in Table 2.

In our series, we analysed the results of FNAC of thyroid nodules in 5017 patients, of which 574 with initially benign results underwent repeated FNAC. Thyroid carcinoma with initially benign cytology was found in 13 patients $(2.3 \%)$ upon repeated FNAC. This result is in agreement with other series. The duration of the follow-up period still remains a question. Relevant data from longer studies are limited. Different authors propose time intervals ranging from 6 to 12 months (38) up to 3 years or more (22). In our series, the interval was variable depending on referral of patients for follow-up investigation. Malignancy can be detected even in an interval of 10 years in a relatively stable nodule.

A detailed look at histologically verified malignant tumours with FNAC result changed from benign to suspicious (Table 3) shows that initial cytological results were almost exclusively cases of Hashimoto's thyroiditis 
Table 3 Detailed look at 13 histologically verified malignancies with initially benign cytology.

\begin{tabular}{|c|c|c|c|c|c|c|}
\hline $\begin{array}{l}\text { Patient } \\
\text { No. }\end{array}$ & $\begin{array}{l}\text { Initial cytological } \\
\text { result (s) }\end{array}$ & $\begin{array}{c}\text { Subsequent } \\
\text { cytological result }\end{array}$ & Histology & $\begin{array}{l}\text { Nodule size } \\
\text { at first } \\
\text { FNAC }(\mathrm{mm})\end{array}$ & $\begin{array}{l}\text { Tumour } \\
\text { size }(\mathrm{mm})\end{array}$ & $\begin{array}{c}\text { Interval } \\
\text { between } \\
\text { FNACs (month) }\end{array}$ \\
\hline 1 & $\mathrm{HT}$ & Susp carcinoma & $\begin{array}{l}\text { Poorly differentiated } \\
\text { carcinoma }\end{array}$ & 60 & 90 & 13 \\
\hline 2 & $\begin{array}{l}\text { Colloid goitre with } \\
\text { regressive changes }\end{array}$ & Follicular neoplasia & FVPC & 25 & 30 & 83 \\
\hline 3 & Benign & Follicular neoplasia & PC & & & 31 \\
\hline 4 & $\mathrm{HT}$ & Follicular neoplasia & MC & 25 & 30 & 24 \\
\hline 5 & $\begin{array}{l}\text { Cyst and regressive } \\
\text { changes }\end{array}$ & Follicular neoplasia & FC & 33 & 25 & 57 \\
\hline 6 & Follicular adenoma & Follicular neoplasia & PC & 9 & 15 & 39 \\
\hline 7 & $\begin{array}{l}\text { Colloid goitre with } \\
\text { regressive changes }\end{array}$ & Susp PC & FC & 8 & 12 & 32 \\
\hline 8 & $\mathrm{HT}$ & Follicular neoplasia & FC & 16 & 18 & 13 \\
\hline 9 & HT & Oncocytic tumour & FC & 20 & 27 & 79 \\
\hline 10 & Microfollicular adenoma & Susp PC & PC & & 20 & 131 \\
\hline 11 & $\mathrm{HT}$ & Susp PC & FVPC & 16 & 26 & 63 \\
\hline 12 & HT & Susp PC & PC & 19 & 19 & 48 \\
\hline \multirow[t]{3}{*}{13} & $\begin{array}{l}\text { Colloid goitre with } \\
\text { regressive changes }\end{array}$ & Follicular neoplasia & FVPC & 14 & 31 & 66 \\
\hline & & & & & Mean & 52 \\
\hline & & & & & Median & 50 \\
\hline
\end{tabular}

HT, Hashimoto's thyroiditis; PC, papillary carcinoma; FC, follicular carcinoma; MC, medullar carcinoma; FVPC, follicular variant of papilocarcinoma.

or with severe regressive changes. First FNAC specimens were for the purpose of our study and were all re-evaluated by a single experienced cytopathologist (A R). In the majority of cases, the false negative result was considered as misinterpretation of the cytological features, and the sample should have been classified as suspicious. In three cases, prominent regressive changes in the tumour were the cause of misinterpretation that precluded recognition of characteristic tumour features. These specimens should have been qualified as nondiagnostic. In one case, only the first FNAB was clearly benign colloidal goitre, and the nodule was probably missed by the initial fine-needle biopsy. When regressive changes are present, repetition of FNAC should be therefore always considered. Similar to other retrospective studies, we have also found several limitations in our survey. Various periods between subsequent FNACs are present depending on when patients were referred for second investigation. FNAC was not repeated systematically in all patients so that selection bias is probable. Cases with suspicious US characteristics, FNAC result other than unequivocal colloidal goitre, and growing nodules were aspirated more frequently. Not all of the patients were operated on, and carcinoma cannot be ruled out with certainty when the histopathological examination was not performed. Carcinoma was present in $22.41 \%$ of the operated nodules with suspicious results of repeated FNAC. Carcinoma was also present in $6.54 \%$ in initially benign FNAC results remaining benign on repetition. These results represent in all ten cases papillary microcarcinomas with no clinical significance, present distant of the investigated nodule. To the contrary, the malignancies discovered on the basis of suspicious results of repeated FNAC were clinically important tumours larger than $10 \mathrm{~mm}$ misdiagnosed on the first evaluation. The size of the nodule did not change considerably in the majority of papillary carcinomas.

These results confirm the usefulness of repeated aspiration during follow-up in patients with initially benign FNAC result. In our series, it was able to identify malignancy missed at first FNAC in $2.3 \%$ of cases. Usually, it corrected misinterpretation of samples by cytopathologists, especially when the initial result was other than colloidal goitre. We believe that repeating FNAC in patients with benign cytology in about a 1-year horizon can reduce the rate of undiagnosed tumours.

\section{Declaration of interest}

The authors declare that there is no conflict of interest that could be perceived as prejudicing the impartiality of the scientific work reported. F Gabalec, J Ćáp, A Ryška, T Vašátko and V Ceeová have nothing to declare.

\section{Funding}

This work was supported by the Charles University Grant Agency (grant number 79008).

\section{References}

1 Tunbridge WM, Evered DC, Hall R, Appleton D, Brewis M, Clark F, Evans JG, Young E, Bird T \& Smith PA. The spectrum of thyroid disease in a community: the Whickham survey. Clinical Endocrinology 19777 481-493.

2 Dean DS \& Gharib H. Epidemiology of thyroid nodules. Best Practice and Research. Clinical Endocrinology and Metabolism 2008 22 901-911. 
3 Mazzaferri EL. Management of a solitary thyroid nodule. New England Journal of Medicine 1993328 553-559.

4 Wang C \& Crapo LM. The epidemiology of thyroid disease and implications for screening. Endocrinology and Metabolism Clinics of North America 199726 189-218.

5 Hegedus L. Clinical practice. The thyroid nodule. New England Journal of Medicine 2004351 1764-1771.

6 Cappelli C, Castellano M, Pirola I, Cumetti D, Agosti B, Gandossi E \& Agabiti Rosei E. The predictive value of ultrasound findings in the management of thyroid nodules. Quarterly Journal of Medicine $200710029-35$.

7 Iannuccilli JD, Cronan JJ \& Monchik JM. Risk for malignancy of thyroid nodules as assessed by sonographic criteria: the need for biopsy. Journal of Ultrasound in Medicine 200423 1455-1464.

8 McHenry CR, Huh ES \& Machekano RN. Is nodule size an independent predictor of thyroid malignancy? Surgery 2008144 1062-1068 (discussion 1068-1069).

9 Morris LF, Ragavendra N \& Yeh MW. Evidence-based assessment of the role of ultrasonography in the management of benign thyroid nodules. World Journal of Surgery 200832 1253-1263.

10 Hegedus L. Thyroid ultrasound. Endocrinology and Metabolism Clinics of North America 200130 339-360.

11 Cooper DS, Doherty GM, Haugen BR, Kloos RT, Lee SL, Mandel SJ, Mazzaferri EL, McIver B, Sherman SI \& Tuttle RM. Management guidelines for patients with thyroid nodules and differentiated thyroid cancer. Thyroid 200616 109-142.

12 Frates MC, Benson CB, Charboneau JW, Cibas ES, Clark OH, Coleman BG, Cronan JJ, Doubilet PM, Evans DB, Goellner JR, Hay ID, Hertzberg BS, Intenzo CM, Jeffrey RB, Langer JE, Larsen PR, Mandel SJ, Middleton WD, Reading CC, Sherman SI \& Tessler FN. Management of thyroid nodules detected at US: Society of Radiologists in Ultrasound consensus conference statement. Radiology 2005237 794-800.

13 Gharib H, Papini E, Valcavi R, Baskin HJ, Crescenzi A, Dottorini ME, Duick DS, Guglielmi R, Hamilton CR Jr, Zeiger MA \& Zini M. American Association of Clinical Endocrinologists and Associazione Medici Endocrinologi medical guidelines for clinical practice for the diagnosis and management of thyroid nodules. Endocrine Practice 200612 63-102.

14 Gharib H \& Goellner JR. Fine-needle aspiration biopsy of the thyroid: an appraisal. Annals of Internal Medicine $1993 \mathbf{1 1 8}$ 282-289.

15 Cap J, Ryska A, Rehorkova P, Hovorkova E, Kerekes Z \& Pohnetalova D. Sensitivity and specificity of the fine needle aspiration biopsy of the thyroid: clinical point of view. Clinical Endocrinology 199951 509-515.

16 Cap J \& Ryska A. Aspirační cytologie štítné žlázy. Hradec Králové: Nucleus HK, 2003.

17 Gharib H. Changing concepts in the diagnosis and management of thyroid nodules. Endocrinology and Metabolism Clinics of North America 199726 777-800.

18 Gutman PD \& Henry M. Fine needle aspiration cytology of the thyroid. Clinics in Laboratory Medicine 199818 461-482 vi.

19 Gharib H, Papini E \& Paschke R. Thyroid nodules: a review of current guidelines, practices, and prospects. European Journal of Endocrinology 2008159 493-505.

20 Wiersinga WM. Is repeated fine-needle aspiration cytology indicated in (benign) thyroid nodules? European Journal of Endocrinology $1995132661-662$.

21 Chehade JM, Silverberg AB, Kim J, Case C \& Mooradian AD. Role of repeated fine-needle aspiration of thyroid nodules with benign cytologic features. Endocrine Practice 20017 237-243.

22 Illouz F, Rodien P, Saint-Andre JP, Triau S, Laboureau-Soares S, Dubois S, Vielle B, Hamy A \& Rohmer V. Usefulness of repeated fine-needle cytology in the follow-up of non-operated thyroid nodules. European Journal of Endocrinology 2007156 303-308.
23 Flanagan MB, Ohori NP, Carty SE \& Hunt JL. Repeat thyroid nodule fine-needle aspiration in patients with initial benign cytologic results. American Journal of Clinical Pathology 2006 125 698-702.

24 Aguilar J, Rodriguez JM, Flores B, Sola J, Bas A, Soria T, Ramirez P \& Parrilla P. Value of repeated fine-needle aspiration cytology and cytologic experience on the management of thyroid nodules. Otolaryngology and Head and Neck Surgery $1998119121-124$.

25 Erdogan MF, Kamel N, Aras D, Akdogan A, Baskal N \& Erdogan G. Value of re-aspirations in benign nodular thyroid disease. Thyroid 19988 1087-1090.

26 Shin JH, Han BK, Ko K, Choe YH \& Oh YL. Value of repeat ultrasound-guided fine-needle aspiration in nodules with benign cytological diagnosis. Acta Radiologica 200647 469-473.

27 Orlandi A, Puscar A, Capriata E \& Fideleff H. Repeated fineneedle aspiration of the thyroid in benign nodular thyroid disease: critical evaluation of long-term follow-up. Thyroid $2005 \mathbf{1 5}$ 274-278.

28 Menendez Torre E, Pineda Arribas J, Martinez de Esteban JP, Lopez Carballo MT, de Miguel C \& Salvador P. Value of repeated fine needle aspiration cytology in patients with nodular goiter. Acta Cytologica $2007 \mathbf{5 1} 850-852$.

29 Cap J, Ryska A, Hovorkova E, Rehorkova P \& Kerekes Z. Value of the repeated fine-needle aspiration biopsy in the follow-up of thyroid disease. Thyroid 20002 17-25.

30 Dwarakanathan AA, Staren ED, D'Amore MJ, Kluskens LF, Martirano M \& Economou SG. Importance of repeat fine-needle biopsy in the management of thyroid nodules. American Journal of Surgery 1993166 350-352.

31 Hamburger JI. Consistency of sequential needle biopsy findings for thyroid nodules. Management implications. Archives of Internal Medicine 1987147 97-99.

32 Mittendorf EA \& McHenry CR. Follow-up evaluation and clinical course of patients with benign nodular thyroid disease. American Surgeon 199965 653-657 (discussion 657-658).

33 Kessler A, Gavriel H, Zahav S, Vaiman M, Shlamkovitch N, Segal S \& Eviatar E. Accuracy and consistency of fine-needle aspiration biopsy in the diagnosis and management of solitary thyroid nodules. Israel Medical Association Journal 20057 371-373.

34 Lucas A, Llatjos M, Salinas I, Reverter J, Pizarro E \& Sanmarti A. Fine-needle aspiration cytology of benign nodular thyroid disease. Value of re-aspiration. European Journal of Endocrinology 1995132 677-680.

35 Morosini PP, Mancini V, Filipponi S, Taccaliti A, Ferretti M, Gusella P, Vecchi A, Fianchini A \& Fabris G. Comparison between the diagnostic accuracy in diagnosis of thyroid nodules with fine needle biopsy an intraoperative histological evaluation of frozen tissue. Minerva Endocrinologica 199722 1-5.

36 Merchant SH, Izquierdo R \& Khurana KK. Is repeated fine-needle aspiration cytology useful in the management of patients with benign nodular thyroid disease? Thyroid 200010 489-492.

37 Morosini PP, Filipponi S, Mancini V, Taccaliti A, Simonella G, Ferretti M, Gusella P \& Vecchi A. Evaluation of the role of repeat needle biopsy in the diagnosis and follow-up of thyroid nodules. Minerva Endocrinologica 199621 59-62.

38 Burch HB, Burman KD, Reed HL, Buckner L, Raber T \& Ownbey JL. Fine needle aspiration of thyroid nodules. Determinants of insufficiency rate and malignancy yield at thyroidectomy. Acta Cytologica $1996 \mathbf{4 0} 1176-1183$.

Received 10 September 2009

Accepted 11 September 2009 